\title{
Dithiocarbamates as Selective Ligands for Polarographic Study of Manganese(II) at DME
}

\author{
C. GIRIDHAR, S. KANCHI, T. NIRANJAN and N. VENKATASUBBA NAIDU* \\ Department of Chemistry, S. V. University, Tirupathi-517502, A.P., India \\ nvsn69@gmail.com
}

Received 22 November 2013 / Accepted 28 December 2013

\begin{abstract}
Two new ligands, ammonium 2,6-dimethyl morpholine dithiocarbamate (ADMMDTC) and ammonium 3-methyl piperdine dithiocarbamate (AMP-DTC) were synthesized in the laboratory. The method was based on chelation of manganese(II) with ADMM-DTC/AMP-DTC in the presence of $\mathrm{NH}_{4} \mathrm{OH}$ at $\mathrm{pH} 6.2$ and 6.8 to produce catalytic hydrogen currents at $-0.72 \mathrm{~V}$ and $-0.62 \mathrm{~V}$ vs. SCE respectively and prior detected by D.C poarography. Optimized polarographic conditions were established by studying effect of $\mathrm{pH}$, supporting electrolyte $\left(\mathrm{NH}_{4} \mathrm{Cl}\right)$, ligand and metal ion concentrations and effect of adverse ions on peak height to improve the sensitivity, selectivity and detection limits of the present method. This technique is successfully applied for the analysis of manganese(II) in different matrices with recoveries ranging from $97-99 \%$ and the results obtained were comparable with the differential pulse polarography (DPP).
\end{abstract}

Keywords: D.C. polarography, Catalytic hydrogen current technique, Manganese(II), Ammonium 2,6dimethyl morpholine dithiocarbamate, ADMM-DTC, Ammonium 3-methyl piperidine dithiocarbamate, Differential pulse polarography

\section{Introduction}

Manganese is a trace element, which plays a significant role in metabolism of man, animals and plants. Manganese is commonly found throughout most aquatic environments. Manganese has several oxidation states. The most stable and important one is the divalent state, $\mathrm{Mn}$ (II) that forms a series of complexes with number of chelating agents. The average daily intake of adult is 2.2-2.7 mg of manganese. Bowen ${ }^{1}$ found normal human blood to have an average of $24 \pm 8 \mathrm{mg}$. Manganese deficiency has been observed in man with a vitamin K deficiency ${ }^{2}$. Haemoglobin levels do not appear to be significantly affected by lack of manganese $e^{3,4}$. Manganese toxicity is a serious constraint to crop cultivation since it is taken-up by plants and can easily be passed into the food chain again causing symptoms of Parkinson's disease. The impairment in mucopolysaccharide synthesis associated with manganese deficiency has been related to the activation of glycosyl transferases by this element ${ }^{5}$.

The analysis of manganese in biological and environmental samples is usually performed using radio-analytical and absorption spectrophotometric methods. These instruments 
are not available in all laboratories due to sophisticated conditions required and cost involved. An alternative method is therefore developed for trace analysis of manganese(II) using simple D.C. polarograph available in most of the laboratories utilizing the catalytic hydrogen currents of manganese-dthiocarbamate complexes in $\mathrm{NH}_{4} \mathrm{Cl}$ medium. The method is applied for the analysis of $\mathrm{Mn}$ (II) in soil, agricultural and environmental samples $^{6}$. It is enviable to develop a simple, sensitive, selective, rapid and cost effective method for the determination of manganese(II) in different matrices by synthesizing ADMM-DTC and AMP-DTC that gives catalytic hydrogen currents with the metal at DME. The results of this method is reported here which is more sensitive than our earlier reported ones.

\section{Experimental}

The current-voltage curves are recorded using a D.C.polarographic analyzer, model CL-357 coupled with model LR-101 strip chart recorder manufactured by Elico Private Ltd (Hyderabad, India). Effects of mercury height on polarographic currents are studied using D.C. recording polarograph model Cl-25 of Elico Pvt Ltd, Hyderabad.

\section{Differential pulse polarograph}

The current-voltage curves are recorded using polarographic analyzer, model CL-362 coupled with optional printer manufactured by Elico Private Limited (Hyderabad, India). All pH measurements are made using pH meter, model LI-120(Elico Pvt. Limited, India) with combined electrode of $\mathrm{pH}$ range $0-13$.

\section{Reagents}

All reagents were of analytical grade and deionized doubly distilled water was used for preparation of all solutions. 2,6-Dimethyl morpholine, 3-methyl Piperidine, carbon disulphide, ammonium chloride and ammonia solution were purchased from S.D. Fine Chemicals, Mumbai, India and used in the present investigation. Standard solution of cobalt $\left(1 \mu \mathrm{gmL}^{-1}\right.$ ) was prepared by weighing $3.074 \mathrm{~g}$ of $\mathrm{MnSO}_{4} .7 \mathrm{H}_{2} \mathrm{O}$ (SD. Fine Chemicals, Mumbai, India) and dissolved in de-ionized doubly distilled water and made up to the mark in 1,000 $\mathrm{mL}$ standard flask.

ADMM-DTC $(0.01 \mathrm{M})$ was prepared by weighing $0.208 \mathrm{~g}$ of ADMM-DTC and dissolved in $100 \mathrm{~mL}$ de-ionized doubly distilled water. AMP-DTC $(0.01 \mathrm{M})$ was prepared by weighing $0.192 \mathrm{~g}$ of AMP-DTC and dissolved in $100 \mathrm{~mL}$ de-ionized doubly distilled water. Freshly prepared solution was stored in dark colored bottle. Stock solutions of ADMM-DTC, AMP-DTC and $\mathrm{NH}_{4} \mathrm{Cl}$ were prepared by appropriate addition of reagents and chemicals in $250 \mathrm{~mL}$ standard flask and stored in dark place.

\section{Synthesis of ammonium 2,6-dimethyl morpholine dithiocarbamate (ADMM-DTC) and ammonium 3-methyl piperidine dithiocarbamate (AMP-DTC)}

Carbon disulphide (40 g) was slowly added to a solution of 2,6-dimethyl morpholine/ 3-methyl piperidine $\left(45 \mathrm{~g}\right.$ ) in $25 \mathrm{~mL}$ of de-ionized doubly distilled water at $5{ }^{\circ} \mathrm{C}$ with constant stirring, followed by ammonium hydroxide. The product (Scheme 1 and 2) was warmed to room temperature and washed repeatedly two to three times with purified acetone. The reaction product was purified by recrystallization in acetone $\mathrm{e}^{7 \mathbf{1 0}}$. The purified compounds have melting points of $176-182{ }^{\circ} \mathrm{C}$ (Amm 2,6-dimethyl Mor-DTC) and $192-195{ }^{\circ} \mathrm{C}$ (Amm 3-methyl Pip-DTC) at $740 \mathrm{~mm}$ pressure. 
<smiles>CC1CNCC(C)O1</smiles>

2-6-dimethyl Morpholine<smiles>CC1CN(C(=S)SN)CC1C</smiles>

Scheme 1. Synthesis of ammonium 2-6-dimethyl morpholine dithiocarbamate (ADMM-DTC)<smiles>CC1CCCNC1</smiles><smiles>CC1CCCN(C([NH])=S)C1</smiles>

Scheme 2. Synthesis of ammonium 3-methyl piperidine dithiocarbamate (AMP-DTC)

\section{Procedure}

General procedure for the determination of manganese(II) with catalytic hydrogen current technique at dropping mercury electrode using dithiocarbamates (Amm 2,6-dimethyl MorDTC and Amm 3-methyl Pip-DTC).

A measured volume of the $\mathrm{NH}_{4} \mathrm{Cl}$, supporting electrolyte and ligands (ADMM-DTC and AMP-DTC) were added to the electroactive species [Mn(II)], maintaining the optimum $\mathrm{pH}$ and the solution was made up to $100 \mathrm{~mL}$ in a standard flask with de-ionized doubly distilled water and then transferred to the polarographic cell. The dissolved oxygen was expelled by bubbling pure nitrogen through the analyte solution for $15 \mathrm{~min}$. Polarograms of the solutions was recorded using D.C Polarography. Dithiocarbamates (ADMM-DTC and AMP-DTC) or simple metal ions in the medium do not give any peak current at the potentials of catalytic hydrogen currents (CHC;-0.72 V and $-0.62 \mathrm{~V}$ vs. SCE). Typical current-voltage curves at DME in the quantitative experimental conditions are presented in Figure 1a-b.

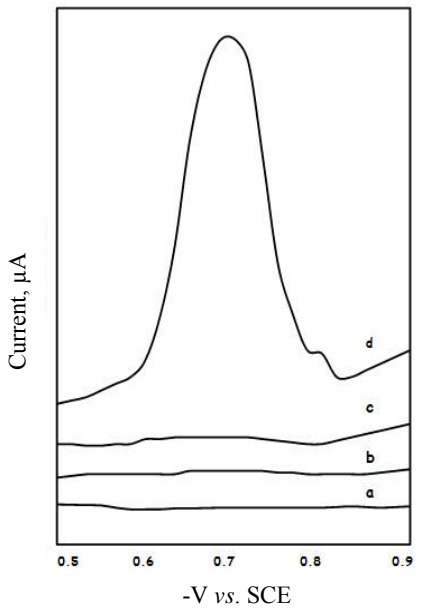

Figure 1a. Polarographic curve of Manganese(II) in $\mathrm{NH}_{4} \mathrm{Cl}-\mathrm{NH}_{4} \mathrm{OH}$ medium in the presence of Amm 2,6-dimethyl MorDTC (a) $0.3 \mathrm{M} \mathrm{NH}_{4} \mathrm{Cl}, \mathrm{pH} \sim 6.2$ (b) a+3.8 mM Amm 2,6-dimethyl Mor-DTC (c)a+ 3.0 ppm $\mathrm{Mn}(\mathrm{II})$ (d) b+3.0 ppm $\mathrm{Mn}(\mathrm{II})$

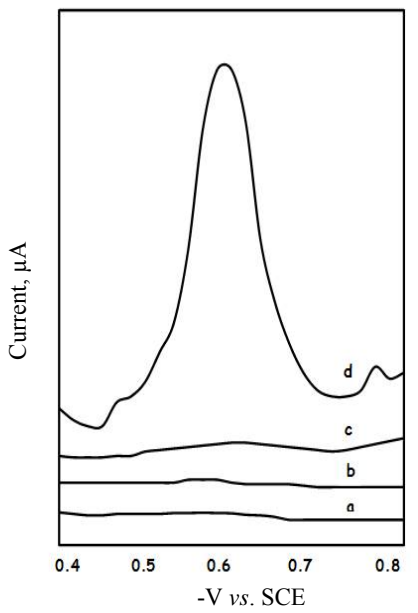

Figure 1b. Polarographic curve of Manganese(II) in $\mathrm{NH}_{4} \mathrm{Cl}-\mathrm{NH}_{4} \mathrm{OH}$ medium in the presence of Amm 3-methyl Pip-DTC (a) $0.4 \mathrm{M} \mathrm{NH}_{4} \mathrm{Cl}, \mathrm{pH} \sim 6.8$ (b) a+3.8 $\mathrm{mM} \mathrm{Amm}$ 3-methyl Pip-DTC (c) a+3.0 ppm Mn(II) (d) b+3.0 ppm $\mathrm{Mn}(\mathrm{II})$ 


\section{Results and Discussion}

Various optimal conditions developed for the determination of manganese(II) at DME are reported below.

\section{Effect of $p H$}

The effect of $\mathrm{pH}$ on solutions containing $3.0 \mathrm{ppm}$ of manganese(II) ion in $0.5 \mathrm{M}$ ammonium chloride was studied, using $3.0 \mathrm{mM}$ of ADMM-DTC/AMP-DTC as complexing agents, varying the $\mathrm{pH}$ from 5.0 to 10.0 adjusting with ammonium hydroxide. With increasing $\mathrm{pH}$, the height of the catalytic wave increased and after attaining a maximum peak current $[\mathrm{pH}$ 6.2 (ADMM-DTC) and 6.8 (AMP-DTC)] the wave height decreased with further increase in $\mathrm{pH}$. The maximum wave height of the polarograms was selected as optimum $\mathrm{pH}$, which was maintained in all other studies. The results are graphically presented in Figure 2.

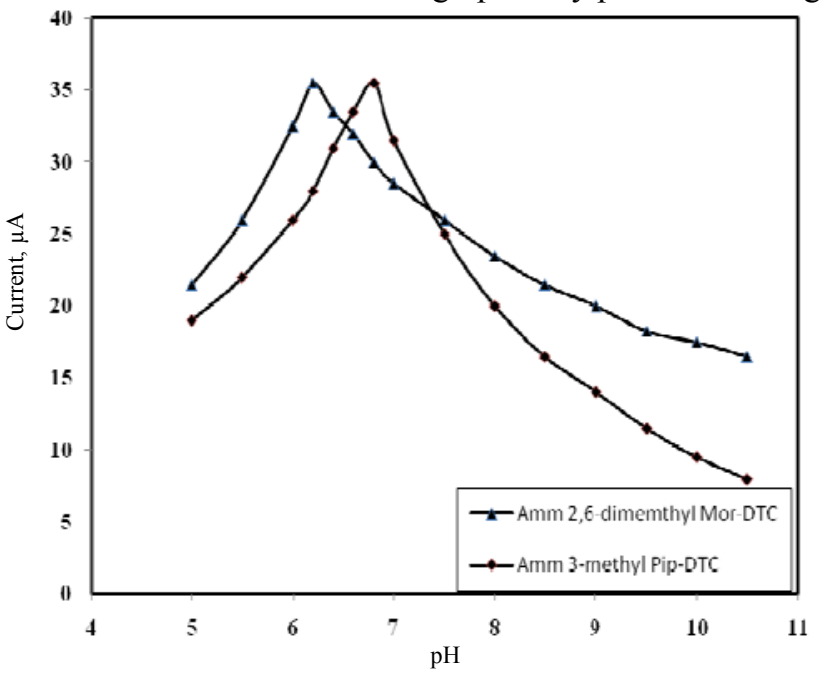

Figure 2. Effect of $\mathrm{pH}$ for the determination of manganese(II) with Amm 2,6-dimethyl MorDTC and Amm 3-methyl Pip-DTC

\section{Effect of supporting electrolyte concentration}

The effect of ammonium chloride in the range of 0.1 to $0.6 \mathrm{M}$ on the nature of currentvoltage curves at dropping mercury electrode (DME), keeping the $\mathrm{Mn}$ (II) concentration at $3.0 \mathrm{ppm}$ and dithiocarbamate concentration at $3.0 \mathrm{mM}$ (ADMM-DTC)/(AMP-DTC) and adjusting the $\mathrm{pH}$ to 6.2 (ADMM-DTC) or 6.8 (AMP-DTC). The polarogram are well defined in $\mathrm{NH}_{4} \mathrm{Cl}$ of $0.3 \mathrm{M}$ for ADMM-DTC and $0.4 \mathrm{M}$ for AMP-DTC. The peak height decreased beyond this concentration and therefore, $0.3 \mathrm{M}$ for ADMM-DTC and 0.4 M for AMP-DTC concentration was maintained for further studies and the results obtained are given in Figure 3.

\section{Effect of reagent concentration}

Series of solutions containing $3.0 \mathrm{ppm}$ of manganese(II), $0.3 \mathrm{M}$ and $0.4 \mathrm{M}$ ammonium chloride for ADMM-DTC and AMP-DTC respectively with 2.0 to $6.0 \mathrm{mM}$ dithiocarbamates (ADMM-DTC and AMP-DTC) were polarographed, maintaining the $\mathrm{pH}$ of the solution at 6.2 in case of ADMM-DTC and 6.8 for AMP-DTC. The peak current does not vary linearly with all concentrations of ligand, which is a typical characteristic nature of catalytic waves, and the results obtained are represented graphically in Figure 4. From the results, it is seen 
that the wave height increased linearly with dithiocarbamate concentration up to $3.8 \mathrm{mM}$ for both ADMM-DTC and AMP-DTC. With further increase in dithiocarbamate concentration, the wave height was independent of concentration indicating that the complex was stable. Therefore, the concentration of the ligands where the maximum wave height obtained is fixed for quantitative studies. The peak potential of the catalytic wave shifted towards more negative potentials on increasing the dithiocarbamate concentration, up to the maximum concentration reported above and remained constant beyond these concentrations. Plot of $\left\{\left[\right.\right.$ Dithiocarbamate] / $\left.i_{p}\right\}$ vs. [Dithiocarbamate] was a straight line (Figure 5) and confirms that adsorption phenomenon was involved in the electrode reaction process.

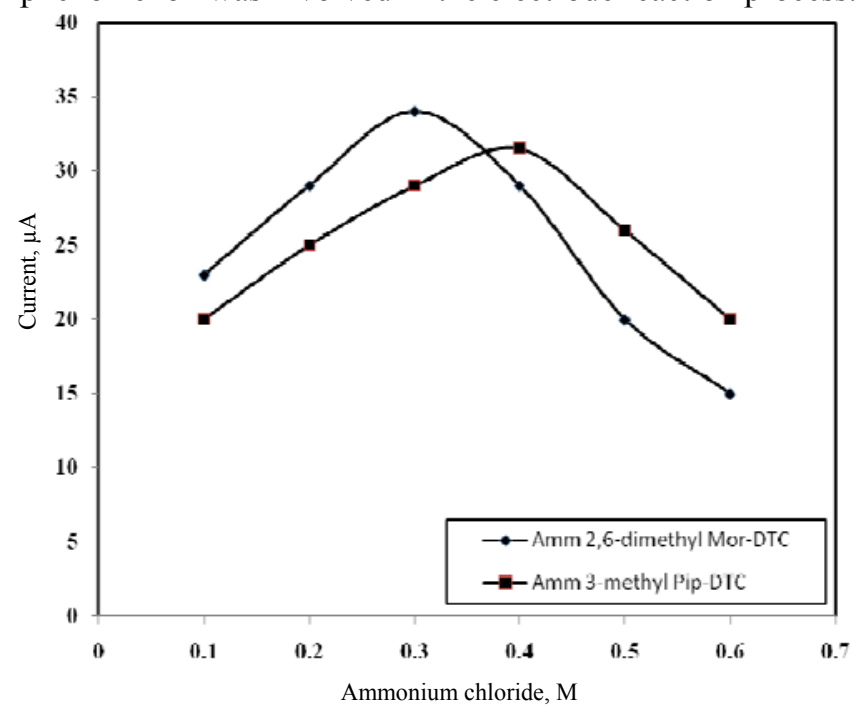

Figure 3. Effect of supporting electrolyte for the determination of manganese(II) with Amm 2,6-dimethyl Mor-DTC and Amm 3-methyl Pip-DTC

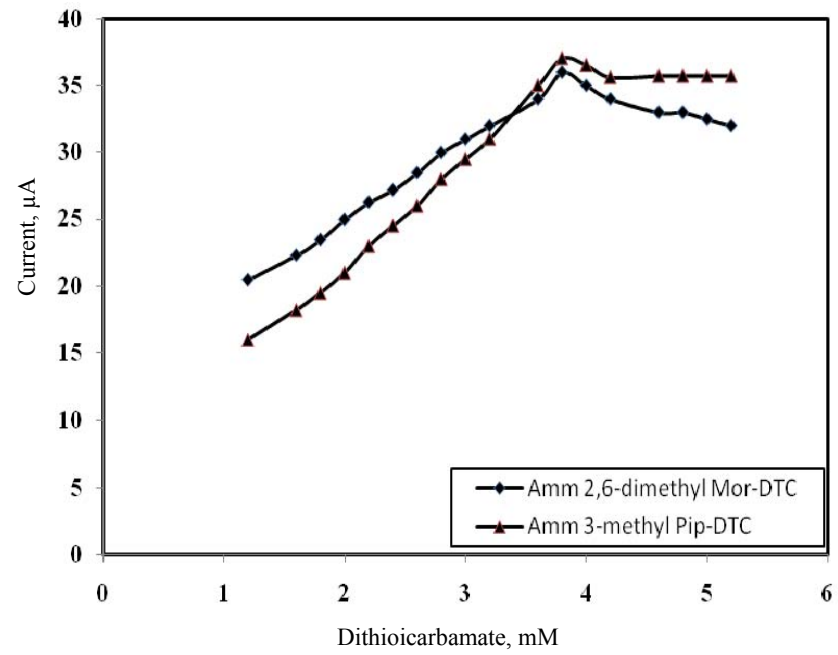

Figure 4. Effect of reagent concentration for the determination of manganese(II) with Amm 2,6-dimethyl Mor-DTC and Amm 3-methyl Pip-DTC 


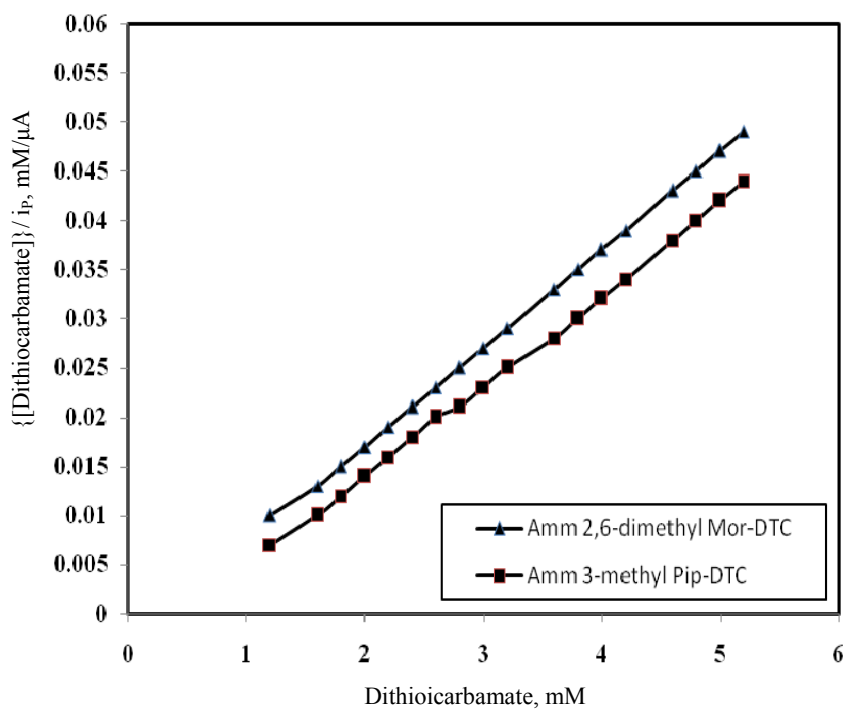

Figure 5. Langmuir adsorption isotherm plot for the determination of manganese(II) with Amm 2,6-dimethyl Mor-DTC and Amm 3-methyl Pip-DTC

\section{Effect of mercury pressure}

The effect of the height of the mercury column on the polarograms of manganese(II)3.0 ppm in quantitative experimental conditions was investigated and found that the catalytic current as well as $i_{C} / \sqrt{h}$ decreased with the height of the mercury column indicating that the current is catalytic in nature and the experimental observations are recorded in Table 1.

Table 1. Effect of mercury pressure for the determination of manganese(II) with Amm 2,6-dimethyl Mor-DTC and Amm 3-methyl Pip-DTC

\begin{tabular}{ccccc}
\hline \multirow{2}{*}{$\begin{array}{c}\text { Height of the mercury } \\
\text { column, cm }\end{array}$} & \multicolumn{2}{c}{ Amm 2,6-dimethyl Mor-DTC } & \multicolumn{2}{c}{ Amm 3-methyl Pip-DTC } \\
\cline { 2 - 5 } & Current, $\mu \mathrm{A}$ & $i_{C} / \sqrt{h}$ & current, $\mu \mathrm{A}$ & $i_{C} / \sqrt{h}$ \\
\hline 21 & 37.00 & 1020 & 36.00 & 1010 \\
26 & 36.50 & 978 & 33.50 & 965 \\
31 & 35.75 & 850 & 31.75 & 850 \\
36 & 35.25 & 758 & 30.25 & 775 \\
\hline
\end{tabular}

\section{Effect of maximum suppressor}

The effect of surface active substances, gelatine in the range 0.005 to $0.01 \%$ and Triton $\mathrm{X}-100$, of 0.002 to $0.004 \%$ on the catalytic wave height was studied maintaining the fixed analytical concentrations developed for two dithiocarbamates (ADMM-DTC and AMP-DTC). The analytical data obtained are presented in Table 2. The catalytic wave decreases sharply up to $0.005 \%$ gelatine concentration and further increase in concentration of the surface-active material suppresses the wave further by only about $2 \%$. The peak potential shifted towards positive potentials and the catalytic peak became round shaped. The suppression of the catalytic wave with 0.002 to $0.005 \%$ triton $\mathrm{x}-100$ was small when compared to gelatine. The peak potential shifted towards positive potentials in this case also. 
Table 2. Effect of maximum suppressors for the determination of manganese(II) with Amm 2,6-dimethyl Mor-DTC and Amm 3-methyl Pip-DTC

\begin{tabular}{cccc}
\hline \multirow{2}{*}{ S. No } & Maximum & \multicolumn{2}{c}{ Current, $\mu \mathrm{A}$} \\
\cline { 3 - 4 } & suppressor, $\%$ & Amm 2,6-dimehtyl Mor-DTC & Amm 3-methyl Pip-DTC \\
\hline Gelatin & & & \\
1 & 0.000 & 36.00 & 35.50 \\
2 & 0.005 & 25.50 & 25.25 \\
3 & 0.010 & 24.50 & 25.00 \\
Triton x-100 & & & 35.00 \\
1 & 0.000 & 36.00 & 25.50 \\
2 & 0.002 & 25.25 & 25.00 \\
3 & 0.004 & 24.50 & \\
\hline
\end{tabular}

\section{Effect of temperature}

The current-voltage curve of the systems with the two dithiocarbamates (ADMM-DTC and AMP-DTC) were recorded at various temperatures, i.e., 15 to $45{ }^{\circ} \mathrm{C}$ and found that with increase in temperature, the wave height increased and temperature coefficient values decreased gradually. The current, $\mathrm{i}_{\mathrm{c}}$ became completely temperature independent above $30^{\circ} \mathrm{C}$.

\section{Effect of manganese(II) concentration on peak current}

At fixed concentration of dithiocarbamate, (3.8 mM ADMM-DTC and AMP-DTC) and (0.3 M for Amm 2,6-dimethyl Mor-DTC and 0.4 M for Amm 3-methyl Pip-DTC) ammonium chloride adjusting the $\mathrm{pH}$ to 6.2 and 6.8 , respectively the metal ion concentration was varied between 0.05 to $6.0 \mathrm{ppm}$ and its effect on the current-voltage curve was studied. The peak current increased linearly with manganese(II) concentration in the range 0.05 to $4.0 \mathrm{ppm}$ in case of both dithiocarbamates (ADMM-DTC and AMP-DTC). However, the sensitivity of the method was more with AMP-DTC compared to ADMM-DTC because of strong complex of manganese(II) with AMP-DTC and increased catalytic activity. The calibration plot is shown if Figure 6. The method suggests that the determination of micro-amount of manganese(II) is possible in unknown samples. It was observed that there was no change in the shape of the wave throughout the manganese(II) concentration range studied.

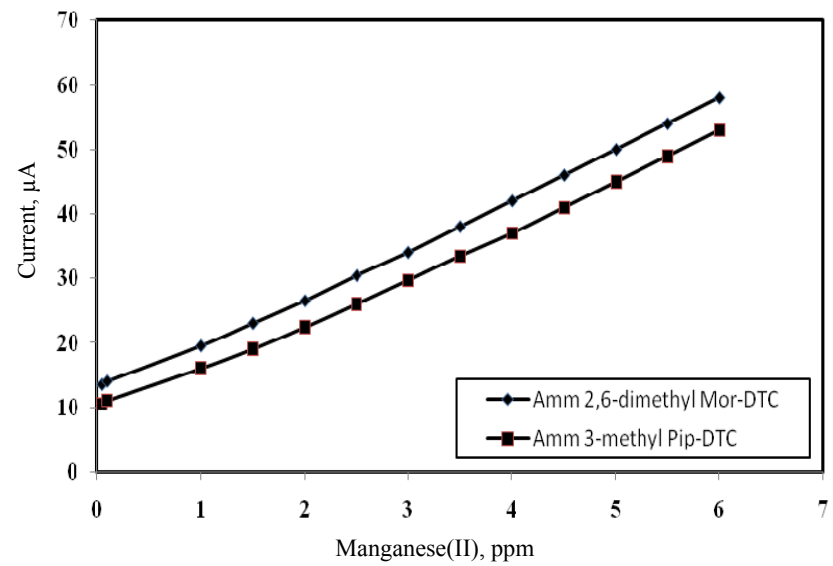

Figure 6. Effect of manganese(II) on peak current for the determination of manganese(II) with Amm 2,6-dimethyl Mor-DTC and Amm 3-methyl Pip-DTC 


\section{Effect of foreign ions}

The effect of transition metal ions like $\mathrm{Co}(\mathrm{II}), \mathrm{Ni}(\mathrm{II}), \mathrm{Cu}(\mathrm{II}), \mathrm{Fe}(\mathrm{II})$ and $\mathrm{Cr}(\mathrm{VI})$ which are commonly associated with manganese(II), on the nature and height of the catalytic wave of manganese was studied using $3.0 \mathrm{ppm}$ manganese in the quantitative experimental conditions developed. These metal ions do not interfere with manganese(II) due to its specific conditions. $\mathrm{Ni}(\mathrm{II})$ gets precipitated below $\mathrm{pH} 9.0$ and $\mathrm{Fe}(\mathrm{II})$ at $\mathrm{pH} 8.0$ and above which can be filtered off. $\mathrm{Cr}(\mathrm{VI})$ does not interfere even when present up to 100 -fold excess as its peak potential was negative to that of manganese(II). The other metal ions such as cadmium(II), mercury(II), vanadium(V), magnesium(II), lead(II),aluminium(III), silver(I), uranium(VI), selenium(IV), tellurium(IV), cerium(IV), tin(IV), do not interferes with Mn(II) even in 100 fold excess and $\mathrm{Zn}$ (II) up to $20 \mathrm{ppm}$. The only metal ion, molybdenum(VI) interferes seriously by increasing the wave height and shifting the peak potential of the manganese(II) catalytic wave. Anions such as fluoride, bromide, iodide, tartrate, sulfate, thiosulfate, perchlorate, carbonate, thiocyanate and phosphate do not interfere with manganese(II) catalytic wave. Oxalate, citrate and EDTA interfere by completely suppressing the manganese catalytic wave, whereas nitrite and nitrate interfere by increasing the catalytic wave height.

\section{Effect of indifferent cations}

The effect of neutral salt and replacement of monovalent cation with divalent cation leads to changes both in the height and in the potential location of the catalytic wave. The concentration of $\mathrm{NH}_{4} \mathrm{Cl}$ in the solution was kept constant and several amounts of different chlorides were added to the polarographed solutions of 3.0-ppm $\mathrm{Mn}$ (II) in fixed concentrations of dithiocarbamates (ADMM-DTC and AMP-DTC) at corresponding $\mathrm{pH}$ values. Three alkali chlorides potassium, sodium and lithium and bivalent cation, calcium were used. With increase in concentration of chlorides, the wave height decreased continuously and the decrease of wave height in sodium chloride is slightly less to that of potassium chloride. The decrease is more for lithium chloride and much more for calcium chloride as shown in Figure $7 \mathrm{a}$ and $\mathrm{b}$.

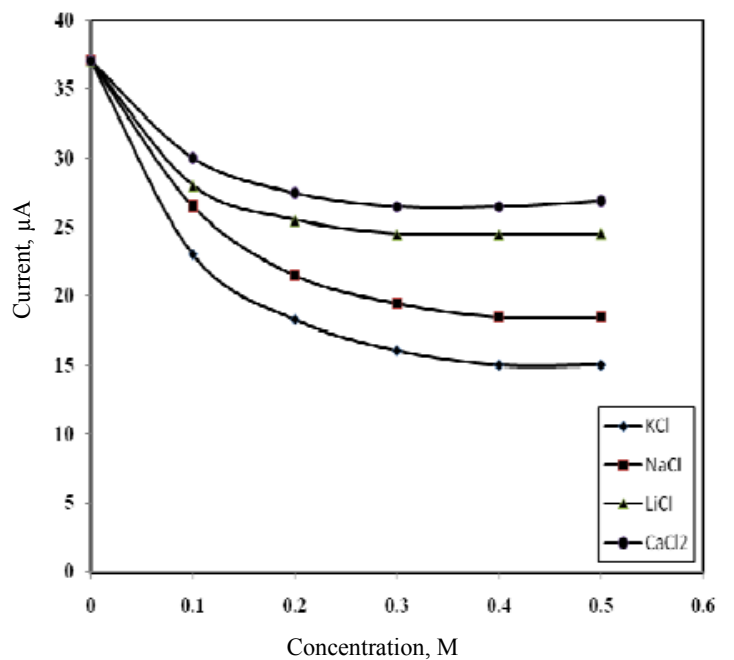

Figure 7a. Effect of indifferent ions on Amm 2,6-dimethyl Mor-DTC-manganese(II) complex at dropping mercury electrode(DME) for the determination of manganese(II) in various water samples and leafy vegetables using catalytic hydrogen current $(\mathrm{CHC})$ technique 


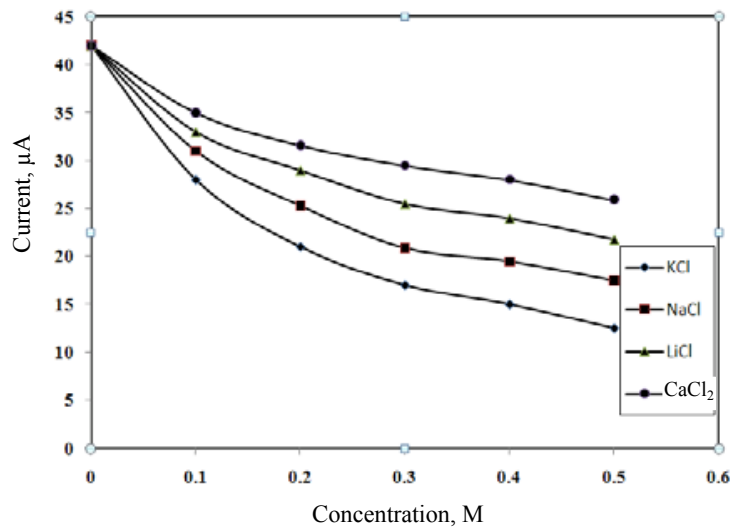

Figure 7b. Effect of indifferent ions on Amm 3-methyl Pip-DTC-manganese(II) complex at dropping mercury electrode(DME) for the determination of manganese(II) in various water samples and leafy vegetables using catalytic hydrogen current(CHC) technique

\section{Methods of evaluation}

The present $\mathrm{CHC}$ technique is critically evaluated with regard to reproducibility, accuracy and detection limits for analysis of manganese(II) in various water samples, vegetable samples.

\section{Reproducibility}

To test reproducibility of the $\mathrm{CHC}$ technique for $\mathrm{Mn}(\mathrm{II})$, six repetitive analysis of each sample were run. A \% R.S.D in the range of 2.25 to 2.97 was obtained as shown in Tables 3-6.

\section{Accuracy}

The accuracy of the present $\mathrm{CHC}$ technique was evaluated by comparing the results with those obtained by the other methods already reported in these laboratories and also with the differential pulse polarography (DPP) method. The analytical data presented in Tables 3-6 shows that the present $\mathrm{CHC}$ technique is more sensitive than the earlier reported methods of these laboratories.

Table 3. Determination of manganese(II) with Amm 2,6-dimethyl Mor-DTC in drinking water samples collected around Tirupati, Chittoor District, A.P. India using catalytic hydrogen current $(\mathrm{CHC})$ technique

\begin{tabular}{cccccc}
\hline \multirow{2}{*}{ Sample $^{\mathrm{a}}$} & $\begin{array}{c}\text { Mn(II) } \\
\text { added, ppm }\end{array}$ & \multicolumn{2}{c}{ CHC method (DC Polarography) } & \multicolumn{2}{c}{ DPP method } \\
\cline { 3 - 6 } & \multicolumn{2}{c}{$\begin{array}{c}\text { Amm 2,6-dimethyl Mor-DTC } \\
\text { Mn(II) found, } \\
\text { ppm }\end{array}$} & $\begin{array}{c}\text { Recovery \% } \\
\pm \text { R.S.D }\end{array}$ & $\begin{array}{c}\text { Mn(II) found, } \\
\text { ppm }\end{array}$ & $\begin{array}{c}\text { Recovery } \% \\
\pm \text { R.S.D }\end{array}$ \\
\hline \multirow{4}{*}{ I } & 0.2 & 0.315 & $99.00 \pm 2.55$ & 0.310 & $98.50 \pm 2.54$ \\
& 0.4 & 0.520 & $98.75 \pm 2.67$ & 0.520 & $98.75 \pm 2.56$ \\
& 0.6 & 0.730 & $98.33 \pm 2.33$ & 0.725 & $98.16 \pm 2.53$ \\
& 0.8 & 0.895 & $99.37 \pm 2.41$ & 0.905 & $99.75 \pm 2.57$ \\
& 1.0 & 1.210 & $100.00 \pm 2.88$ & 1.190 & $99.00 \pm 2.99$ \\
II & 0.2 & 0.299 & $98.50 \pm 2.55$ & 0.299 & $100.00 \pm 2.99$ \\
& 0.4 & 0.474 & $97.50 \pm 2.40$ & 0.425 & $97.50 \pm 2.53$ \\
& 0.6 & 0.696 & $99.33 \pm 2.38$ & 0.690 & $98.66 \pm 2.61$ \\
& 0.8 & 0.950 & $99.75 \pm 2.66$ & 0.946 & $99.00 \pm 2.48$ \\
& 1.0 & 1.115 & $98.00 \pm 2.57$ & 1.190 & $100.00 \pm 2.57$ \\
\hline
\end{tabular}

I Industrial Estate; II Amara raja Batteries, ${ }^{a}$ Five millilitres of the concentrated sample is used, ${ }^{b}$ Relative standard deviation $(n=6)$ 
Table 4. Determination of manganese(II) with Amm 3-methyl Pip-DTC in Drinking Water Samples collected around Tirupati, Chittoor District, A.P. India using catalytic hydrogen current $(\mathrm{CHC})$ technique

\begin{tabular}{|c|c|c|c|c|c|}
\hline \multirow{3}{*}{ Sample $^{\mathrm{a}}$} & \multirow{3}{*}{$\begin{array}{l}\mathrm{Mn}(\mathrm{II}) \\
\text { added, } \\
\text { ppm }\end{array}$} & \multirow{2}{*}{\multicolumn{2}{|c|}{$\begin{array}{c}\text { CHC method } \\
\text { (DC Polarography) } \\
\text { Amm 3-methyl Pip-DTC }\end{array}$}} & \multicolumn{2}{|c|}{ DPP method } \\
\hline & & & & \multicolumn{2}{|c|}{ Amm 3-methyl Pip-DTC } \\
\hline & & $\begin{array}{c}\mathrm{Mn}(\mathrm{II}) \\
\text { found, } \mathrm{ppm}\end{array}$ & $\begin{array}{l}\text { Recovery \% } \\
\pm \text { R.S.D }\end{array}$ & $\begin{array}{l}\text { Mn(II) found, } \\
\text { ppm }\end{array}$ & $\begin{array}{c}\text { Recovery \% } \\
\pm \text { R.S.D }\end{array}$ \\
\hline \multirow{5}{*}{ I } & 0.2 & 0.310 & $98.25 \pm 2.45$ & 0.301 & $97.50 \pm 2.54$ \\
\hline & 0.4 & 0.517 & $98.25 \pm 2.57$ & 0.517 & $98.25 \pm 2.56$ \\
\hline & 0.6 & 0.710 & $98.0 \pm 2.23$ & 0.715 & $98.50 \pm 2.53$ \\
\hline & 0.8 & 0.885 & $99.30 \pm 2.61$ & 0.878 & $99.25 \pm 2.57$ \\
\hline & 1.0 & 1.200 & $99.75 \pm 2.98$ & 1.190 & $99.50 \pm 2.69$ \\
\hline \multirow{5}{*}{ II } & 0.2 & 0.279 & $99.50 \pm 2.55$ & 0.290 & $100.00 \pm 2.49$ \\
\hline & 0.4 & 0.450 & $97.50 \pm 2.30$ & 0.402 & $97.50 \pm 2.50$ \\
\hline & 0.6 & 0.700 & $98.33 \pm 2.58$ & 0.680 & $99.75 \pm 2.55$ \\
\hline & 0.8 & 0.950 & $99.75 \pm 2.26$ & 0.936 & $99.00 \pm 2.50$ \\
\hline & 1.0 & 1.150 & $100.00 \pm 2.47$ & 1.150 & $100.00 \pm 2.97$ \\
\hline
\end{tabular}

I Industrial Estate; II Amara raja Batteries, ${ }^{a}$ Five millilitres of the concentrated sample is used, ${ }^{b}$ Relative standard deviation $(n=6)$

Table 5. Determination of manganese(II) with Amm 2,6-dimethyl Mor-DTC in leafy vegetables and medicinal plant samples around Tirupati, Chittoor District, A.P. India using catalytic hydrogen current $(\mathrm{CHC})$ technique

\begin{tabular}{|c|c|c|c|c|c|}
\hline \multirow{3}{*}{ Sample ${ }^{a}$} & \multirow{3}{*}{$\begin{array}{c}\mathrm{Mn}(\mathrm{II}) \\
\text { Added, ppm- }\end{array}$} & \multicolumn{2}{|c|}{$\begin{array}{c}\text { CHC method } \\
\text { (DC Polarography) }\end{array}$} & \multicolumn{2}{|c|}{ DPP method } \\
\hline & & \multicolumn{2}{|c|}{ Amm 2,6-dimethyl Mor-DTC } & \multicolumn{2}{|c|}{ Amm 3-methyl Pip-DTC } \\
\hline & & $\begin{array}{c}\text { Mn(II) } \\
\text { found, ppm }\end{array}$ & $\begin{array}{l}\text { Recovery \% } \\
\pm \text { R.S.D }\end{array}$ & $\begin{array}{c}\mathrm{Mn}(\mathrm{II}) \\
\text { found, } \mathrm{ppm}\end{array}$ & $\begin{array}{l}\text { Recovery, } \\
\% \pm \text { R.S.D }\end{array}$ \\
\hline $\begin{array}{l}\text { Leafy Vegetable } \\
\text { Ammaranthyus } \\
\text { graecizans/ } \\
\text { Sirraku } \\
\text { Ammaranthus }\end{array}$ & 3.0 & 3.09 & $99.00 \pm 2.25$ & 3.00 & $98.50 \pm 2.54$ \\
\hline $\begin{array}{l}\text { cruentus/ } \\
\text { Thottakura }\end{array}$ & 3.0 & 3.04 & $98.25 \pm 2.42$ & 3.05 & $98.75 \pm 2.44$ \\
\hline \multicolumn{6}{|l|}{ Medicinal Plants } \\
\hline $\begin{array}{l}\text { Calotropis } \\
\text { gigantean/ } \\
\text { Thella gilleddu }\end{array}$ & 3.0 & 3.03 & $98.50 \pm 2.54$ & 3.09 & $99.00 \pm 2.39$ \\
\hline $\begin{array}{l}\text { Cassia } \\
\text { auriculatel } \\
\text { Thangeddu }\end{array}$ & 3.0 & 3.11 & $99.75 \pm 2.30$ & 3.12 & $100.00 \pm 2.92$ \\
\hline
\end{tabular}

${ }^{a}$ Five millilitres of the concentrated sample is used, ${ }^{b}$ Relative standard deviation $(n=6)$ 
Table 6. Determination of manganese(II) with Amm 3-methyl Pip-DTC in leafy vegetables and medicinal Plant samples around Tirupati, Chittoor District, A.P. India using catalytic hydrogen current $(\mathrm{CHC})$ technique

\begin{tabular}{|c|c|c|c|c|c|}
\hline \multirow{3}{*}{ Sample $^{\mathrm{a}}$} & \multirow{3}{*}{$\begin{array}{c}\mathrm{Mn}(\mathrm{II}) \\
\text { Added, ppm }\end{array}$} & \multirow{2}{*}{\multicolumn{2}{|c|}{$\begin{array}{c}\text { CHC method } \\
\text { (DC Polarography) } \\
\text { Amm 3-methyl Pip-DTC }\end{array}$}} & \multicolumn{2}{|c|}{ DPP method } \\
\hline & & & & \multicolumn{2}{|c|}{ Amm 3-methyl Pip-DTC } \\
\hline & & $\begin{array}{c}\mathrm{Mn}(\mathrm{II}) \\
\text { found, ppm }\end{array}$ & $\begin{array}{c}\text { Recovery \% } \\
\pm \text { R.S.D }{ }^{\mathrm{b}}\end{array}$ & $\begin{array}{c}\mathrm{Mn}(\mathrm{II}) \\
\text { found, ppm }\end{array}$ & $\begin{array}{c}\text { Recovery \% } \\
\pm \text { R.S.D }\end{array}$ \\
\hline \multicolumn{6}{|c|}{ Leafy Vegetables } \\
\hline $\begin{array}{l}\text { Ammaranth } \\
\text { graecizans/ } \\
\text { Sirraku }\end{array}$ & 3.0 & 3.07 & $99.00 \pm 2.25$ & 3.01 & $98.00 \pm 2.54$ \\
\hline $\begin{array}{l}\text { Ammaranth } \\
\text { cruentus/ } \\
\text { Thottakura }\end{array}$ & 3.0 & 3.04 & $98.00 \pm 2.42$ & 3.05 & $98.50 \pm 2.34$ \\
\hline \multicolumn{6}{|c|}{ Medicinal Plants } \\
\hline $\begin{array}{l}\text { Calotropis } \\
\text { gigantean/ } \\
\text { Thella } \\
\text { gilleddu }\end{array}$ & 3.0 & 3.10 & $98.50 \pm 2.54$ & 3.09 & $98.00 \pm 2.35$ \\
\hline $\begin{array}{l}\text { Cassia } \\
\text { auriculate/ } \\
\text { Thangeddu }\end{array}$ & 3.0 & 3.11 & $98.70 \pm 2.30$ & 3.12 & $100.00 \pm 2.62$ \\
\hline
\end{tabular}

${ }^{a}$ Five millilitres of the concentrated sample is used, ${ }^{b}$ Relative standard deviation ( $\left.n=6\right)$

\section{Detection limits}

This technique was applied for the determination of manganese(II) at DME in various water samples, vegetable samples using newly synthesized Amm 2,6-dimethyl Mor-DTC and Amm 3-methyl Pip-DTC up to 0.001 ppm levels.

\section{Applications}

The CHC technique developed is applied for the determination of traces of manganese(II) in various water samples and vegetable samples.

\section{Analysis of manganese(II) in various water samples}

One liter of the water samples collected from Industrial Estate and Amararaja batteries (Tirupati town, Chittor Dt.) are preconcentrated and analyzed.

\section{Analysis of manganese(II) in leafy vegetable samples}

$3.5 \mathrm{~g}$ of Leafy vegetable samples and medicinal plant (leaves) samples were collected from local sources and digested by dry ash method ${ }^{11}$. The mass was made up to $100 \mathrm{~mL}$ with triple distilled water. Aliquots of the above solution are taken and polarographed using conditions developed. The results obtained by this method are further supported by DPP method and typical polarogram is shown in Figure 8a and $8 \mathrm{~b}$. 


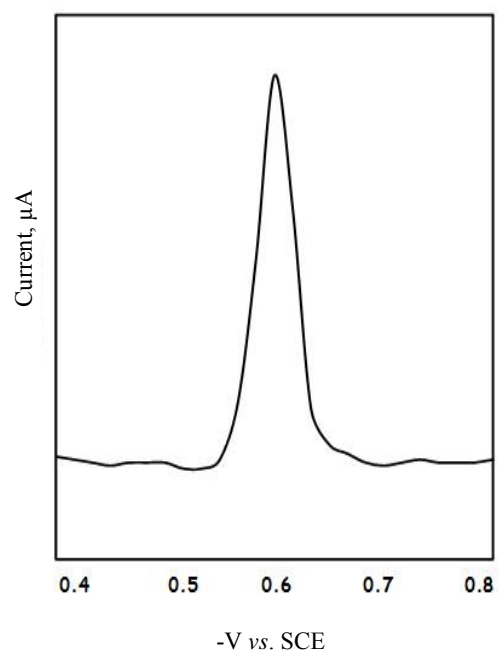

Figure 8a. Differential pulse polarographic curve for the determination of manganese(II) in $\mathrm{NH}_{4} \mathrm{Cl}-\mathrm{NH}_{4} \mathrm{OH}$ medium in the presence of Amm 2,6-dimethyl Mor-DTC. Current Range: $100 \mu \mathrm{A}$, Scan rate: $6 \mathrm{~m} \mathrm{~V} / \mathrm{S}$, Pulse Amplitude: $50 \mathrm{mV}$, Drop time: $1 \mathrm{Sec}$, Manganese(II): 0.001 ppm

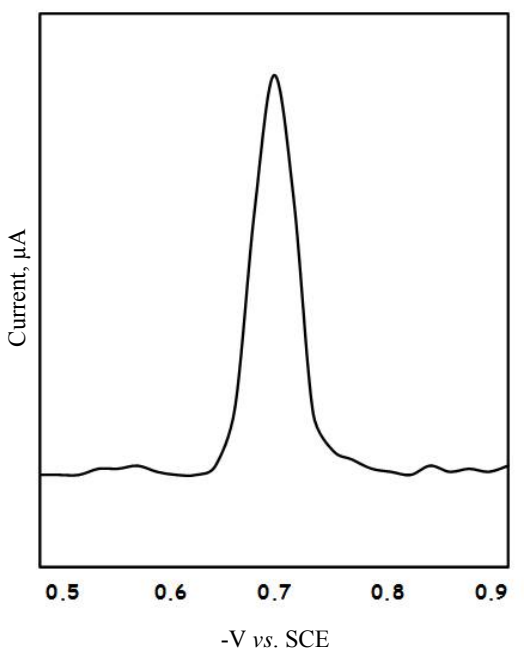

Figure 8b. Differential pulse polarographic curve for the determination of manganese(II) in $\mathrm{NH}_{4} \mathrm{Cl}-\mathrm{NH}_{4} \mathrm{Cl}$ medium in the presence of Amm 3-methyl Pip-DTC. Current range: $100 \mu \mathrm{A}$, Scan rate: $6 \mathrm{~m} \mathrm{~V} / \mathrm{S}$, Pulse amplitude: $50 \mathrm{mV}$, Drop time: $1 \mathrm{Sec}$, Manganese(II): 0.001 ppm

\section{Conclusion}

The polarographic reduction of manganese(II) in aqueous solution in the presence of dithiocarbamate exhibits a catalytic wave as a function of concentration of supporting electrolyte, dithiocarbamate, $\mathrm{pH}$, metal ion. These effects are studied to establish the catalytic character of the complex. The graph of the catalytic current as a function of the concentration of dithiocarbamate shows that the peak current does not vary linearly with the concentration of dithiocarbamate, which is typical of Brdicka catalytic hydrogen waves ${ }^{12}$. It is assumed that the dithiocarbamate complexes with metal ions involve adsorption process and can be described by a Langmuir adsorption isotherm ${ }^{13}$ and the plot of $C_{L} / i_{p} v s . C_{L}$ should be linear. Such a plot is found with manganese complexes of dithiocarbamates studied as shown in Figure 5. The decrease of catalytic peak current with increase in mercury column height also suggests that the wave is kinetically controlled ${ }^{14}$.

Effect of ionic strength of indifferent cations explains the adsorption process. The presence of an indifferent electrolyte diminishes the peak height and this effect is correlated with the adsorption and catalytic nature of manganese-dithiocarbamate complexes on mercury, which is characteristic of catalytic surface reactions ${ }^{15,16}$.

It is known that the surface catalytic currents are almost independent of temperature, and these currents increase at high temperatures, which is a deviation from purely kinetic behaviour. This is because an increase of the rate constant of protonation of the catalyst is compensated by a decrease in its adsorptivity on the electrode surface ${ }^{17}$.

\section{References}

1. Bowen H J M, J Nucl Energy, 1956, 3(1-2), 18-24; DOI:10.1016/0891-3919(56)90036-5 
2. Doisy E A Jr, Trace subst. Environ. Health-6, Proc. Univ. Mo. Annu.Conf., $6^{\text {th }}, 1972$, 1972, P.193 in Trace Element Metabolism in animals, Univ. Parkpress, Baltimore, Maryland, 1974, 2, 249.

3. Smith S E, Medlicott M and Ellis G H, Arch Biochem., 1944, 4, 281-289.

4. Wachtel L W, Elvehjem C A and Hart E B, Am J Physiol., 1943, 140, 72.

5. Leach R. M Jr, Fed Proc Fed Am Soc Exp Biol., 1967, 26,118; 1971, 30, 991.

6. Kanchi S, Saraswathi K and Venkatasubba Naidu N, Food Anal Method., 2012, 5(1), 69-81.

7. Kanchi S, Krishnamurthy P, Saraswathi K and Venkatasubba Naidu N, Chem Technol An Indian J., 2011, 6(1), 6-12.

8. Kanchi S, Niranjan T, Sarawathi K and Venkatasubba Naidu N, Anal Chem: An Indian J., 2011, 10(4), 231-238.

9. Kanchi S, Sulochana M, Babu Naidu K, Saraswathi K and Venkatasubba Naidu N, Food Anal Methods, 2011, 4(4), 453-464.

10. Kanchi S, Singh P, Sabela M I, Bisetty K and Venkatasubba Naidu N, Int $J$ Electrochem Sci., 2013, 8, 4260-4282.

11. Scott W W and Furman N H, Standard Method of Chemical Analysis. Sixth Edition, 1963, 1.

12. Meites L, Polarographic Techniques, Interscience Publishers Inc., New York, 1995, 78.

13. Reilley C N and Stumm W, Progress in Polarography, Edited by Zuman P and Kolthoff I M, Interscience publishers, Inc., London, 1962, I, Chapter V.

14. Kolthoff I M and Lingane J J, Polarography, Interscience Publishers, Inc., New York, $2^{\text {nd }}$ Edition, 1952, I, Chapter XV.

15. Mairanovskii S G, J Electroanal Chem., 1963, 6, 77.

16. Turyan Ya I and Malyavinskaya O N, Electrochim Acta, 1972, 17(10), 1181.

17. Mairanovskii S G, Catalytic and kinetic waves in polarography. Interscience Publishers, Inc., New York, 1968. 